\title{
PENGARUH PENGAWASAN, KOMITMEN PEGAWAI DAN LINGKUNGAN KERJA TERHADAP PRODUKTIVITAS KERJA PEGAWAI DINAS PERDAGANGAN DAN PERINDUSTRIAN KOTA TANJUNGBALAI
}

\author{
${ }^{1}$ Rima Wulandari, ${ }^{2}$ Suwito, ${ }^{3}$ Zulfitri Syawaluddin Hasibuan, ${ }^{4}$ Evan Botung Daulay, ${ }^{5}$ Adi Kuncoro \\ ${ }_{1,2,3,4,5}$ Universitas Islam Sumatera Utara \\ ${ }^{1}$ rima.wulandari@gmail.com, ${ }^{2}$ suwito.mm@gmail.com, ${ }^{3}$ zulfitri.syawaluddin@gmail.com, ${ }^{4}$ evan.botung@gmail.com, \\ 5 adi.kuncoro@gmail.com
}

\begin{abstract}
The formulation of the problem in this study are: How do supervision, employee commitment and work environment influence employee work productivity. This study aims to examine how the influence of supervision, employee commitment and work environment on employee work productivity. With total sampling technique, the sample in this study amounted to 35 people. Supervision variables partially have a positive effect on employee work productivity. Employee commitment variable partially has a positive effect on employee work productivity. Work environment variables partially have a positive effect on employee work productivity. Supervision variables, employee commitment and work environment simultaneously have a positive and significant effect on employee work productivity.
\end{abstract}

Keywords : Supervision; Employee Commitment; Work environment; Work productivity

ABSTRAK : Rumusan masalah dalam penelitian ini adalah : Bagaimana pengaruh pengawasan, komitmen pegawai dan lingkungan kerja terhadap produktivitas kerja pegawai. Penelitian ini bertujuan untuk mengkaji bagaimana pengaruh pengawasan, komitmen pegawai dan lingkungan kerja terhadap produktivitas kerja pegawai. Dengan teknik penarikan sampel secara Total Sampling maka sampel dalam penelitian ini berjumlah 35 orang. Variabel pengawasan secara partial berpengaruh positif terhadap produktivitas kerja pegawai. Variabel komitmen pegawai secara partial berpengaruh positif terhadap produktivitas kerja pegawai. Variabel lingkungan kerja secara partial berpengaruh positif terhadap produktivitas kerja pegawai. Variabel pengawasan, komitmen pegawai dan lingkungan kerja secara simultan berpengaruh positif dan signifikan terhadap produktivitas kerja pegawai.

Kata Kunci : Pengawasan; Komitmen Pegawai; Lingkungan Kerja; Produktivitas Kerja

\section{Pendahuluan}

Indonesia dengan jumlah penduduk yang besar telah memiliki modal sumberdaya, tinggal diusahakan agar jumlah penduduk yang sedemikian besar itu dapat digerakan agar menjadi sumber daya yang produktif. Tingkat pendidikan, keterampilan, sikap profesional serta pengetahuan, jaminan sosial dan pelatihan dibutuhkan agar mendorong dan meningkatkan produktivitas pegawai sebagai faktor pendorong untuk meningkatkan potensi kerja mereka. Salah satu tema bidang ketenagakerjaan adalah tingkat produktivitas kerja yang dimiliki tenaga kerja atau pegawai. Sulaeman (2014: 91) memberikan pendapat bahwa produktivitas kerja pegawai merupakan faktor yang sangat penting dalam menunjang keberhasilan suatu usaha.

Produktivitas merupakan salah satu komponen yang harus dimiliki oleh suatu instansi apabila ingin mencapai tujian yang telah ditetapkan instansi. Dalam kegiatannya instansi harus mampu meningkatkan produktivitasnya dari waktu ke waktu karena menyangkut pada produksi instansi. Peningkatan kualitas, efisien dan ektifitas tidak hanya tergantung paa teknologi mesinmesin modern, modal yang cukup dan adanya bahan baku yang bermutu saja. Namun semua faktor tersebut tidak terjadi apa-apa tanpa adanya dukungan dari sumber daya manusia yang baik dan bisa mengembangkan kemampuan dan keahlian 
mereka serta dapat menunjukkan dalam grafik produktivitas kerja pegawai. Dengan demikian, baik pengusaha maupun pegawai yang terlibat berupaya meningkatkan produktivitasnya, dengan berbagai kebijakan yang secara efisien maupun meningkatkan produktivitas pegawai.

Produktivitas sendiri merupakan suatu kekuatan yang menghasilkan barang dan jasa selain itu juga berdampak pada peningkatan standar hidup. Sedarmayanti (2012: 65) produktivitas kerja bukan semata-mata ditunjukan untuk mendapatkan hasil kerja sebanyak-banyaknya melainkan kualitas untuk kerja juga penting diperhatikan. Sedangkan menurut Hasibun (2012:76) produktivitas kerja adalah perbandingan antara output dengan input, di mana outpunya harus mempunyai nilai tambah dan teknik pengerjaannya yag lebih baik.

Dinas Perdagangan dan Perindustrian Kota Tanjungbalai mempunyai tugas membantu Wali Kota dalam memimpin, mengendalikan dan mengkoordinasikan penyelenggaraan urusan pemerintahan dan pelayanan umum yang menjadi kewenangan Dinas pada Bidang Perdagangan, Industri dan Pengelolaan Pasar. Dalam rangka mewujudkan sistem pemerintahan yang bersih dan berwibawa (good gavernance) serta mewujudkan pelayanan publik yang baik, efisien, efektif dan berkualitas tentunya perlu didukung adanya Sumber Daya Manusia (SDM) aparatur khususnya Pegawai Negeri Sipil (PNS) yang profesional, bertanggungjawab, adil, jujur dan kompeten dalam bidangnya.

Pengawasan merupakan hal yang sangat penting dalam setiap pekerjaan baik dalam institusi negeri maupun swasta. Sebab dengan adanya pengawasan yang baik maka rencana program-program yang akan dilaksanakan akan terselenggara dengan baik. Dengan pengawasan sangat erat kaitannya dengan produktivitas karena tugas pertama sebelum memprroduksi suatu hasil produksi adalah mengadakan perencanaan mengenai apa yang akan dikerjakan. Apabila pengawasan yang dilakukan dengan baik maka produktivitas dapat berjalan dengan baik pula. Dalam usaha pencapaian tujuan tersebut, maka perlu adanya peningkatan produktivitas kerja pegawai. Produktivitas kerja pada hakekatnya meliputi sikap yang senantiasa mempunyai pandangan bahwa metode kerja hari ini harus lebih baik dari hari kemarin, dan hasil yang dapat diraih esok hari harus lebih banyak atau lebih bermutu dari pada hasil yang diraih hari ini

Selain pengawasan faktor lain yang perlu diperhatikan oleh Dinas Perdagangan dan Perindustrian Kota Tanjungbalai adalah lingkungan kerja karena sangat berkaitan erat dengan tinggi rendahnya produktivitas kerja pegawai, apabila lingkungan kerja kurang baik maka dapat memberikan pengaruh yang negatif terhadap produktivitas kerja pegawai, begitu pula sebaliknya. Lingkungan kerja adalah keseluruhan alat perkakas dan bahan yang dihadapi, lingkungan sekitarnya dimana seseorang bekerja, metode kerjanya, serta pengaturan kerjanya baik sebagai perseorangan maupun sebagai kelompok. Suatu kondisi lingkungan kerja dikatakan baik atau sesuai apabila manusia dapat melaksanakan kegiatan secara optimal, sehat, aman dan nyaman. Pada masa sekarang ini banyak persaingan dan tingkat globalisasi yang semakin maju membuat institusi pendidikan khususnya Dinas Perdagangan dan Perindustrian Kota Tanjungbalai dituntut untuk bertahan serta mampu bersaing dengan institusi lainnya dan tetap eksis untuk menghadapi perkembangan jaman yang semakin maju.

Oleh karena itu Dinas Perdagangan dan Perindustrian Kota Tanjungbalai harus mempersiapkan perubahan tersebut. Keberadaan komitmen organisasi sebagai respon efektif di tempat kerja, secara berlahan telah menjadi kompetitor serius bagi jenis respon efektif lainnya seperti produktivitas kerja. Meningkatnya popularitas konsep komitmen organisasi didasarkan pada keyakinan bahwa organisasi memiliki implikasi bukan saja pada pegawai dan organisasi namun juga pada masyarakat (Setiawan dan Ghozali 2015 :78) Sebagai upaya menciptakan komitmen ini perlu diadakan pengintegrasian tujuan antara tujuan organisasi dan tujuan pegawai agar pegawai menjadikan tujuan organisasi sebagai tujuan pribadi. Hal ini akan membuahkan suasana saling mendukung antara pegawai dan organisasi. Lebih lanjut suasana tersebut akan membawa pegawai dengan rela menyumbangkan sesuatu bagi tercapainya tujuan. Selain itu untuk menumbuhkan komitmen, pimpinan juga perlu mengetahui kebutuhan pegawai sehingga dapat 
memenuhinya tepat sesuai dengan apa yang diharapkannya. Pegawai yang memiliki komitmen tinggi akan bisa menjiwai pekerjaannya. Mereka akan bekerja dengan hati dan pikirannya dan memandang pekerjaannya bukan sebuah beban erkaitan dengan pentingnya pengawasan, komitmen pegawai dan lingkungan kerja untuk menilai

Perdagangan dan Perindustrian Kota produktivitas kerja pegawai Dinas kerja yang ditetapkan oleh Kepala Dinas.

Tanjungbalai, Dinas harus memberikan arahan dengan mengomunikasikan perintah dengan baik kepada pegawainya. Dengan didukung oleh keterampilan, sikap dan pengetahuan peagwai yang dimiliki seluruh pegawai, maka produktivitas kerja pegawai akan meningkat

Tabel 1.Indikator Produktivitas Kerja Tahun 2019.

\begin{tabular}{|c|c|c|c|c|}
\hline No & $\begin{array}{l}\text { Indicator } \\
\text { Produktivitas Kerja }\end{array}$ & Satuan & $\begin{array}{c}\text { Kondisi Produktivitas } \\
\text { Kerja Pada Awal } \\
\text { Periode RPJMD }\end{array}$ & $\begin{array}{l}\text { Kondisi Produktivitas } \\
\text { Kerja Pada Akhir } \\
\text { Periode RPJMD }\end{array}$ \\
\hline 1 & $\begin{array}{l}\text { Meningkatkan jumlah industri } \\
\text { yang menerapkan teknologi tepat } \\
\text { guna }\end{array}$ & IKM & $274 \mathrm{IKM}$ & $203 \mathrm{IKM}$ \\
\hline 2 & $\begin{array}{l}\text { Pertumbuhan industry } \\
\text { Kecil }\end{array}$ & $\%$ & 2418 unit & 1841 unit \\
\hline 3 & Pertumbuhan industry menengah & $\%$ & 470 unit & 356 unit \\
\hline 4 & $\begin{array}{l}\text { Peningkatan rekomendasi perizinan } \\
\text { vana dikeluarkan }\end{array}$ & $\%$ & 2982 rekomendasi & 1806 rekomendasi \\
\hline 5 & $\begin{array}{ll}\text { Peningkatan } & \text { nilai } \\
\text { Ekspor } & \end{array}$ & $\%$ & USD 829.955.835,97 & USD 336.652.173,39 \\
\hline 6 & $\begin{array}{l}\text { Pengawasan barang yang beredar di } \\
\text { masyarakat }\end{array}$ & Jenis & 52 jenis & 40 jenis \\
\hline 7 & $\begin{array}{lll}\begin{array}{l}\text { Meningkatnya al UTTP yang } \\
\text { ditera Ulang }\end{array} & \\
\end{array}$ & Unit & 10.000 unit & 7.000 unit \\
\hline 8 & $\begin{array}{l}\text { Pasar tradisional yang } \\
\text { representative }\end{array}$ & Pasar & 6 pasar & 4 pasar \\
\hline 9 & Meningkatnya retribusi pasar & $\mathrm{Rp}$ & Rp 9.258.777.300 & Rp 10.816.806.750 \\
\hline 10 & tradisional modern & Pasar & 3 pasar & 2 pasar \\
\hline
\end{tabular}

Sumber : Dinas Perdagangan dan Perindustrian Kota Tanjungbalai

Berdasarkan tabel 1. menunjukkan bahwa adanya penurunan atas pencapaian produktivitas kerja para pegawai, mesih terlihat adanya pekerjaan yang belum terselesaikan kondisi tersebut menunjukkan adanya keterkaitan antara upaya pengawasan, komitmen, keterampilan, sikap dan pengetahuan serta lingkungan kerja yang harus di tingkatkan demi pencapain produktivitas kerja para pegawai.

Para pegawai harus bisa bekerja sesuai tugas dan ketepatan waktu yang telah ditentukan, karena pekerjaan pegawai berkaitan dengan kepentingan masyarakat yang ada di Kota Tanjungbalai. Dalam hal ini produktivitas kerja pegawai Dinas Perdagangan dan Perindustrian Kota Tanjungbalai dianggap masih belum maksimal, di indikasikan karena pengawasan, komitmen pegawai dan lingkungan kerja yang semakin menurun padahal kompetensi dan komunikasi yang dilakukan sudah terbilang bagus. Atasan kurang memonitoring pekerjaan yang dilakukan pegawai, hal tersebut berdampak pada menurunnya produktivitas kerja pegawai karena sering menunda pekerjaan yang seharusnya bisa diselesaikan tepat waktu dan dengan mutu yang bagus.

\subsection{Rumusan Masalah}

Berdasarkan latar belakang yang di uraikan di atas, maka rumusan masalah dalam penelitian ini adalah :

a. Bagaiman pengaruh pengawasan terhadap produktivitas kerja pegawai Dinas

Perdagangan dan Perindustrian Kota

Tanjungbalai

b. Bagaimana pengaruh komitmen pegawai terhadap produktivitas kerja pegawai Dinas Perdagangan dan Perindustrian Kota Tanjungbalai

c. Bagaimana pengaruh lingkungan kerja terhadap produktivitas kerja pegawai Dinas Perdagangan dan Perindustrian Kota Tanjungbalai 
d. Bagaimana pengaruh pengawasan, komitmen pegawai dan lingkungan kerja secara simultan terhadap produktivitas kerja pegawai Dinas Perdagangan dan Perindustrian Kota Tanjungbalai

\subsection{Batasan Masalah}

Pada penelitian ini peneliti hanya meneliti tentang produktivitas kerja pegawai yang di pengaruhi oleh pengawasan, komitmen pegawai , dan lingkungan kerja pada Dinas Perdagangan dan Perindustrian Kota Tanjungbalai

\subsection{Hioptesis}

Hipotesis penelitian dapat diartikan sebagai jawaban yang bersifat sementara terhadap masalah penelitian, sampai terbukti melalui data yang terkumpul dan harus diuji secara empiris. Menurut Sugiyono (2012:64), "Hipotesis merupakan jawaban sementara terhadap rumusan masalah penelitian, dimana rumusan penelitian telah dinyatakan dalam bentuk kalimat pernyataan Berdasarkan uraian kerangka pemikiran di atas, maka hipotesis penelitian adalah sebagai berikut:

a. Pengawasan berpengaruh terhadap produktivitas kerja pegawai Dinas Perdagangan Dan Perindustrian Kota Tanjungbalai

b. Komitmen pegawai berpengaruh terhadap produktivitas kerja pegawai Dinas Perdagangan Dan Perindustrian Kota Tanjungbalai

c. Lingkungan kerja berpengaruh terhadap produktivitas kerja pegawai Dinas Perdagangan Dan Perindustrian Kota Tanjungbalai

d. Pengawasan, komitmen pegawai dan lingkungan kerja berpengaruh terhadap produktivitas kerja pegawai Dinas Perdagangan Dan Perindustrian Kota Tanjungbalai

\subsection{Tujuan Penelitian}

Berdasarkan rumusan masalah di atas, maka tujuan penelitian ini adalah :

a. Untuk mengetahui pengaruh pengawasan terhadap produktivitas kerja pegawai Dinas Perdagangan dan Perindustrian Kota Tanjungbalai

b. Untuk mengetahui pengaruh komitmen pegawai terhadap produktivitas kerja pegawai Dinas Perdagangan dan Perindustrian Kota Tanjungbalai

c. Untuk mengetahui pengaruh lingkungan kerja terhadap produktivitas kerja pegawai Dinas Perdagangan dan Perindustrian Kota Tanjungbalai

d. Untuk mengetahui pengaruh pengawasan, komitmen pegawai dan lingkungan kerja secara simultan terhadap produktivitas kerja pegawai Dinas Perdagangan dan Perindustrian Kota Tanjungbalai

\section{Metode Penelitian}

\subsection{Populasi}

Populasi adalah wilayah generalisasi yang terdiri atas subjek atau objek yang mempunyai kualitas dan karakteristik tertentu yang ditetapkan oleh peneliti untuk dipelajari dan kemudian ditarik kesimpulannya, Sugiono (2013 :80). Dalam penelitian ini yang menjadi populasi penelitian adalah seluruh Pegawai Negeri Sipil pada Dinas Perdagangan Dan Perindustrian Kota Tanjungbalai yang berjumlah 36 orang, karena Kepala Dinas Perdagangan Dan Perindustrian Kota Tanjungbalai tidak ikut di jadikan populasi pada penelitian ini dan dapat dijelaskan dengan kerangka populasi sebagai berikut :

Tabel 2. Kerangka Populasi Berdasarkan Jabatan Thn. 2020

\begin{tabular}{|r|l|c|}
\hline No & \multicolumn{1}{|c|}{ Jabatan } & Jlh \\
\hline 1 & Sekretaris & 1 \\
\hline 2 & Bendahara & 2 \\
\hline 3 & Kepala Bidang & 3 \\
\hline 4 & Kepala Sub. Bagian & 2 \\
\hline 5 & Kepala Seksi & 9 \\
\hline 6 & Bag. Pengadministarian & 9 \\
\hline 7 & Bag. Analis & 5 \\
\hline 8 & Bag. Pengelola & 2 \\
\hline 9 & Juru Retribusi Jumlah & 3 \\
\hline \multicolumn{2}{|c|}{$\mathbf{3 6}$} \\
\hline
\end{tabular}

Sumber: Dinas Perdagangan Dan Perindustrian Kota Tanjungbalai

\subsection{Sampel}

Sampling Sampel adalah bagian dari populasi yang sengaja dipilih oleh peneliti untuk diamati, sehingga sampel ukurannya lebih kecil dibandingkan populasi dan berfungsi sebagai wakil dari populasi ( Nurhayati, 2012 : 36 ). Teknik pengambilan 
sampel dalam penelitian ini adalah total sampling. Total sampling adalah teknik pengambilan sampel dimana jumlah sampel sama dengan populasi, Sugiyono (2010; 130). Alasan mengambil total sampling karena menurut Sugiyono jumlah populasi yang kurang dari 100 seluruh populasi dijadikan sampel penelitian semuanya

Dengan teknik penarikan sampel secara Total Sampling maka sampel dalam penelitian ini adalah seluruh populasi yaitu Dinas Perdagangan Dan Perindustrian Kota Tanjungbalai sebanyak 35 orang. Karena 1 orang kasi pembinaan dan pengembangan usaha perdagangan sebagai peneliti dalam penelitian ini.

Tabel 3.Kerangka Sampel Berdasarkan Jabatan Thn. 2020

\begin{tabular}{|c|l|c|}
\hline No & \multicolumn{1}{|c|}{ Jabatan } & Jlh \\
\hline 1 & Sekretaris & 1 \\
\hline 2 & Bendahara & 2 \\
\hline 3 & Kepala Bidang & 3 \\
\hline 4 & Kepala Sub. Bagian & 2 \\
\hline 5 & Kepala Seksi & 8 \\
\hline 6 & Bag. Pengadministarian & 9 \\
\hline 7 & Bag. Analis & 5 \\
\hline 8 & Bag. Pengelola & 2 \\
\hline 9 & Juru Retribusi & 3 \\
\hline \multicolumn{2}{|c|}{ Jumlah } & $\mathbf{3 5}$ \\
\hline
\end{tabular}

Sumber: Dinas Perdagangan Dan Perindustrian Kota Tanjungbalai

\subsection{Uji Normalitas}

Pengujian normalitas data bertujuan untuk melihat normal tidaknya sebaran data yang akan dianalisis. Model regresi yang baik adalah distribusi normal atau mendekati normal. Untuk melihat normalitas data ini digunakan pendekatan grafik yaitu Normality Probability Plot.

Deteksi normalitas dengan melihat penyebaran data (titik) pada sumbu diagonal dari grafik. Menurut Santoso (2014:214), dasar pengambilan keputusan adalah:

a. Jika data menyebar disekitar garis diagonal dan mengikuti arah garis diagonal, maka model regresi memenuhi asumsi normalitas.

b. Jika data menyebar jauh dari garis diagonal dan atau tidak mengikuti arah garis diagonal, maka model regresi tidak memenuhi asumsi normalitas.
Pada output SPSS bagian normal P-P Plot of Regresion Standardized Residual, dapat dijelaskan bahwa data-data (titik-titik) cenderung lurus mengikuti garis diagonal sehingga data dalam penelitian ini cenderung berdistribusi normal, seperti terlihat pada gambar dibawah ini.

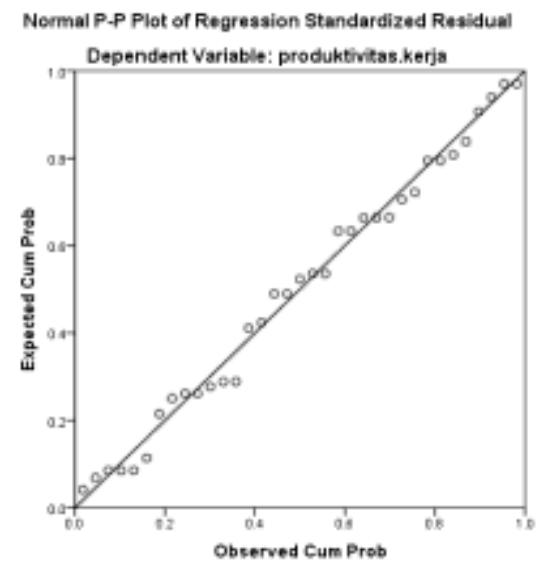

Gambar 1. Normalitas Data

\subsection{Uji Multikolinearitas}

Pengujian multikolinearitas dilakukan untuk melihat apakah pada model regresi ditemukan adanya korelasi antara variabel bebas. Jika terjadi korelasi, maka dinamakan terdapat problem multikolinearitas. Cara mendeteksinya adalah dengan melihat nilai Variance Inflation Factor (VIF). Menurut Santoso (2014; 203), pada umumnya jika VIF lebih besar dari 5, maka variabel bebas tersebut mempunyai persoalan multikolinearitas dengan variabel bebas lainnya.

Pada ouput SPSS bagian Coefficient, semua angka VIF berada dibawah 5, hal ini menunjukan tidak terjadi multikolinearitas, seperti dapat dilihat pada tabel dibawah ini.

Tabel 4. Uji Multikolinearitas

\begin{tabular}{|l|l|c|c|}
\hline \multicolumn{4}{|c|}{ Coefficients $^{\mathbf{a}}$} \\
\hline \multicolumn{2}{|l|}{ Model } & \multicolumn{2}{|c|}{ Collinearity Statistics } \\
\cline { 3 - 4 } & Tolerance & VIF \\
\hline \multirow{2}{*}{1} & (Constant) & & \\
\cline { 2 - 4 } & pengawasan & .739 & 1.353 \\
\cline { 2 - 4 } & komitmen.pegawai & .835 & 1.198 \\
\cline { 2 - 4 } & lingkungan.kerja & .670 & 1.493 \\
\hline
\end{tabular}

a. Dependent Variable: produktivitas.kerja

\subsection{Uji Heteroskedastisitas}

Pengujian heteroskedastisitas bertujuan untuk melihat apakah dalam sebuah model regresi terjadi ketidaksamaan varians dari 
residual yang merupakan suatu pengamatan ke pengamatan yang lainnya. Jika varians dari residual yang merupakan suatu pengamatan ke pengamatan yang lain bernilai tetap, maka hasil data disebut homoskedastisitas dan jika varians berbeda atau bernilai tidak tetap maka disebut heteroskedastisitas. Model regresi yang baik adalah model yang bernilai tetap atau homoskedastisitas atau tidak terjadi heteroskedastisitas.

Deteksi heteroskedastisitas dilakukan dengan cara melihat ada tidaknya pola tertentu pada data yang diolah. Menurut Santoso (2014; 208), dasar pengambilan keputusannya adalah:

a. Jika pola tertentu seperti titik-titik yang ada membentuk suatu pola tertentu yang teratur, maka terdapat situasi heteroskedastisitas.

b. Jika tidak ada pola yang jelas, serta titiktitik menyebar diatas dan dibawah angka nol pada sumbu Y, maka tidak terjadi heteroskedastisitas.

Pada output SPSS dibagian Scatrerplot, terlihat titk-titik menyebar secara acak, tidak membentuk sebuah pola tertentu yang jelas, serta tersebar baik diatas maupun dibawah angka nol pada sumbu Y. Hal ini berarti tidak terjadi heterskedastisitas pada model regresi, sehingga model regresi layak dipakai. Pola Scatterplot dapat dilihat pada gambar dibawah ini.

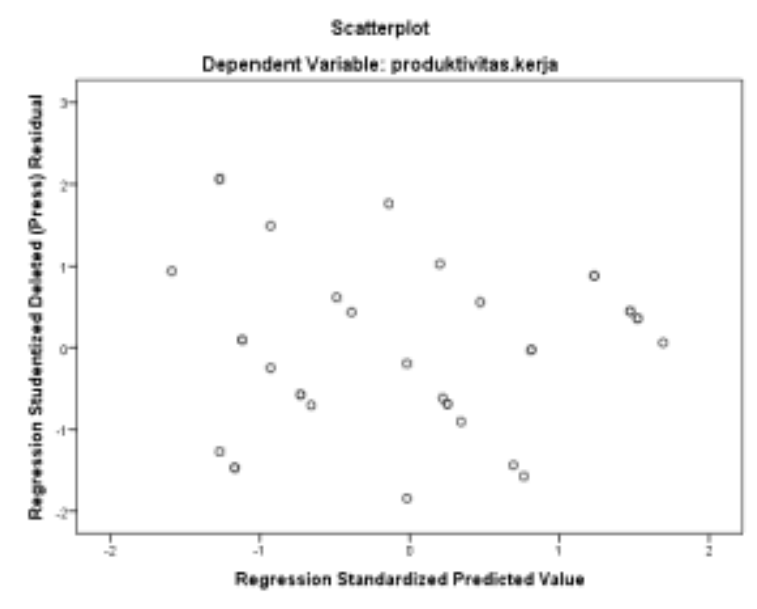

Gambar 2. Uji Heteroskedastitas

\section{Evaluasi Data}

\subsection{Pengujian Hipotesis}

Dalam evaluasi data ini penulis akan melakukan pengujian hipotesis, baik secara partial ataupun secara simultan dengan menggunakan perangkat lunak komputer yaitu program SPSS V.24.00 for windows dengan hasil data sebagai berikut:

Tabel 5. Hasil Uji Statistik Keofesien Regresi

\begin{tabular}{|c|c|c|c|c|c|c|}
\hline \multicolumn{7}{|c|}{ Coefficients $^{\mathrm{a}}$} \\
\hline \multirow{2}{*}{\multicolumn{2}{|c|}{ Model }} & \multicolumn{2}{|c|}{$\begin{array}{l}\text { Unstandardized } \\
\text { Coefficients }\end{array}$} & \multirow{2}{*}{$\begin{array}{c}\text { Standardized } \\
\text { Coefficients } \\
\text { Beta }\end{array}$} & \multirow[t]{2}{*}{$\mathrm{t}$} & \multirow[t]{2}{*}{ Sig. } \\
\hline & & $\mathrm{B}$ & Std. Error & & & \\
\hline \multirow{4}{*}{1} & (Constant) & 2.558 & 4.588 & & .558 & .581 \\
\hline & Pengawasan & .419 & .094 & .466 & 4.476 & .000 \\
\hline & komitmen.pegawai & .237 & .087 & .266 & 2.709 & .011 \\
\hline & lingkungan.kerja & .344 & .100 & .375 & 3.424 & .002 \\
\hline
\end{tabular}

a. Dependent Variable: produktivitas. kerja

Berdasarkan tabel 5. diatas dapat dibuat persamaan regresi sebagai berikut:

$Y=2,558+0,419 X_{1}+0,237 X_{2}+0,344 X_{3}+$

$\varepsilon$

Persamaan diatas dapat dijelaskan bahwa koefesien pengawasan mempunyai nilai positif yaitu 0,419 , hal ini menunujukan bahwa variabel pengawasan memiliki pengaruh yang positif terhadap produktivitas kerja.

Koefesien komitmen pegawai mempunyai nilai positif yaitu 0,237 . Hal ini menunjukan bahwa variabel komitmen pegawai memiliki pengaruh yang positif terhadap produktivitas kerja.

Koefesien lingkungan kerja juga memiliki nilai positif yaitu 0,344 . Hal ini menunjukan bahwa variabel lingkungan kerja juga memiliki pengaruh yang positif terhadap produktivitas kerja.

\subsection{Pengujian Secara Simultan (Uji F)}

Untuk melihat hasil dari model pengujian secara simultan antara variabel pengawasan, komitmen pegawai dan lingkungan kerja terhadap produktivitas kerja pegawai Dinas Perdagangan dan Perindustrian Kota Tanjungbalai terlihat pada tabel di bawah ini : 
Tabel 6. Hasil Uji Statistik Secara Simultan

\begin{tabular}{|l|l|c|c|c|c|c|}
\hline \multicolumn{2}{|l|}{ Model } & $\begin{array}{c}\text { Sum of } \\
\text { Squares }\end{array}$ & df & Mean Square & F & Sig. \\
\hline \multirow{3}{*}{1} & Regression & 39.279 & 3 & 13.093 & 31.206 & \multirow{2}{*}{$000^{\mathrm{b}}$} \\
\cline { 2 - 7 } & Residual & 13.007 & 31 & .420 & & \\
\cline { 2 - 7 } & Total & 52.286 & 34 & & & \\
\hline
\end{tabular}

Dari tabel 6 diatas terlihat bahwa nilai Fhitung adalah 31,206 dan nilai signifikansi 0,000. Diketahui nilai $F_{\text {tabel }}$ dengan tingkat kepercayaan $95 \% \quad(\alpha: 0,05)$ adalah 2,870. Oleh karena itu nilai Fhitung > Ftabel $(31,206$ $>2,870$ ) maka $\mathrm{H}_{\mathrm{O}}$ ditolak dan menerima hipotesis dalam penelitian ini yaitu variabel pengawasan, komitmen pegawai dan lingkungan kerja secara simultan berpengaruh positif dan signifikan terhadap produktivitas kerja pegawai Dinas Perdagangan dan Perindustrian Kota Tanjungbalai.

\subsection{Pengujian Secara Parsial (Uji t)}

\begin{tabular}{|c|c|c|c|c|c|c|}
\hline \multicolumn{7}{|c|}{ Coefficients $^{\mathrm{a}}$} \\
\hline \multirow{2}{*}{\multicolumn{2}{|c|}{ Model }} & \multicolumn{2}{|c|}{$\begin{array}{c}\text { Unstandardized } \\
\text { Coefficients }\end{array}$} & \multirow{2}{*}{$\begin{array}{c}\text { Standardized } \\
\text { Coefficients } \\
\text { Beta } \\
\end{array}$} & \multirow[t]{2}{*}{$\mathrm{t}$} & \multirow[t]{2}{*}{ Sig. } \\
\hline & & $\mathrm{B}$ & Std. Error & & & \\
\hline \multirow{4}{*}{1} & (Constant) & 2.558 & 4.588 & & .558 & .581 \\
\hline & Pengawasan & .419 & .094 & .466 & 4.476 & .000 \\
\hline & komitmen.pegawai & .237 & .087 & .266 & 2.709 & .011 \\
\hline & lingkungan.kerja & .344 & .100 & .375 & 3.424 & .002 \\
\hline
\end{tabular}

a. Dependent Variable: produktivitas. kerja

\subsubsection{Pengaruh $X_{1}$ terhadap $Y$}

Untuk mengetahui secara partial pengaruh variabel pengawasan terhadap produktivitas kerja dapat dilihat pada tebel 7 diatas. Dari tabel tersebut diperoleh nilai thitung sebesar 4,476 dan nilai signifikansi 0,000. Sedangkan nilai tabel pada tingkat kepercayaan $95 \%(\alpha: 0,05)$ adalah 2,021. Oleh karena itu nilai thitung $>$ tabel $(4,476$ $>$ 2,021) maka $\mathrm{H}_{\mathrm{O}}$ ditolak dan menerima hipotesis dalam penelitian ini yaitu variabel pengawasan secara partial berpengaruh positif terhadap produktivitas kerja pegawai Dinas Perdagangan dan Perindustrian Kota Tanjungbalai.

\subsubsection{Pengaruh $\mathrm{X}_{2}$ terhadap $\mathrm{Y}$}

Untuk mengetahui secara partial pengaruh komitmen pegawai terhadap produktivitas kerja, dapat dilihat pada tebel 7 diatas. Dari tabel tersebut diperoleh nilai thitung sebesar 2,709 dan nilai signifikansi 0,011 . Sedangkan nilai tabel pada tingkat kepercayaan 95\% ( $\alpha$ : $0,05)$ adalah 2,021. Oleh karena itu nilai thitung > tabel $(2,709>2,021)$ maka $\mathrm{H}_{\mathrm{O}}$ ditolak dan menerima hipotesis dalam penelitian ini yaitu variabel komitmen pegawai secara partial berpengaruh positif terhadap produktivitas kerja pegawai Dinas Perdagangan dan Perindustrian Kota Tanjungbalai.

\subsubsection{Pengaruh $\mathrm{X}_{3}$ terhadap $\mathrm{Y}$}

Untuk mengetahui secara partial pengaruh lingkungan kerja terhadap produktivitas kerja, dapat dilihat pada tebel 7 diatas. Berdasarkan tabel tersebut diperoleh nilai thitung sebesar 3,424 dan nilai signifikansi 0,002 . Sedangkan nilai tabel pada tingkat kepercayaan 95\% ( $\alpha$ : $0,05)$ adalah 2,021. Oleh karena itu nilai thitung > tabel $(3,424>2,021)$ maka $\mathrm{H}_{\mathrm{O}}$ ditolak dan menerima hipotesis dalam penelitian ini yaitu variabel lingkungan kerja secara partial berpengaruh positif terhadap produktivitas kerja pegawai Dinas Perdagangan dan Perindustrian Kota Tanjungbalai. 
3.4 Uji Koefisien Determinasi $\left(\mathbf{R}^{2}\right)$

Uji determinan adalah untuk mengetahui seberapa besar pengaruh variabel independent terhadap variabel dependent. Untuk melihat hasil uji determinan maka dapat diketahui nili R Square atau koefesien determinasi dan dapat dilihat dibawah ini.

Tabel 8. Model Summary

\begin{tabular}{|l|c|c|c|r|}
\hline Model & $\mathrm{R}$ & $\mathrm{R}$ Square & Adjusted R Square & Std. Error of the Estimate \\
\hline 1 & $.670^{\mathrm{a}}$ & .751 & .727 & .648 \\
\hline \multicolumn{1}{|l|}{ a. Predictors: (Constant), lingkungan.kerja, komitmen.pegawai, pengawasan } \\
\hline
\end{tabular}

Nilai R Square pada tabel 8. diatas adalah 0,751. Ini berarti bahwa $75,10 \%$ produktivitas kerja pegawai Dinas Perdagangan dan Perindustrian Kota Tanjungbalai dapat di jelaskan oleh variabel pengawasan, komitmen pegawai dan lingkungan kerja sedangkan sisanya sebesar $24,90 \%$ di di jelaskan oleh variabel lain yang tidak di teliti.

\section{Kesimpulan}

a. Variabel pengawasan secara partial berpengaruh positif terhadap produktivitas kerja pegawai Dinas Perdagangan dan Perindustrian Kota Tanjungbalai

b. Variabel komitmen pegawai secara partial berpengaruh positif terhadap produktivitas kerja pegawai Dinas Perdagangan dan Perindustrian Kota Tanjungbalai

c. Variabel lingkungan kerja secara partial berpengaruh positif terhadap produktivitas kerja pegawai Dinas Perdagangan dan Perindustrian Kota Tanjungbalai

d. Variabel pengawasan, komitmen pegawai dan lingkungan kerja secara simultan berpengaruh positif dan signifikan terhadap produktivitas kerja pegawai Dinas Perdagangan dan Perindustrian Kota Tanjungbalai

e. Dengan hasil nilai $\mathrm{R}$ Square sebesar 0,751 , hal ini menunjukkan bahwa $75,10 \%$ produktivitas kerja pegawai Dinas Perdagangan dan Perindustrian Kota Tanjungbalai dapat di jelaskan oleh variabel pengawasan, komitmen pegawai dan lingkungan kerja sedangkan sisanya sebesar $24,90 \%$ di jelaskan oleh variabel lain yang tidak di teliti.

\section{DAFTAR PUSTAKA}

Agustin Rozalena dan Sri Komala Dewi. 2014. Panduan Praktis Menyusun
Pengembangan Karier dan Pelatihan Karyawan. Jakarta: Raih Asa Sukses.

Ahyari, Agus. 2010. Manajemen Produksi Perencanaan Sistem Produksi. Yogyakarta: BPFE.

Aji Rachmanto. 2010. Pengaruh faktor komitmen pegawai Terhadap Produktivitas Karyawan Berdasarkan Persepsi Karyawan Bagian Produksi Pada Home Industri Dompet RomanoMojowarno Jombang. Jurnal.

Ardansyah dan Wasilawati. 2014. Analisis

Pengawasan, lingkungan kerja, dan produktivitas kerja Pegawasi Badan Pusat Statistik Kabupaten Lampung Tengah. Jurnal.

Azwar, S. 2017. Metode Penilitan. Yogyakarta: Pustaka Pelajar.

Badriyah, Mila. 2015. Manajemen Sumber Daya Manusia. Bandung :CV Pustaka Setia.

Candra, A.E. 2013. Pengaruh Komitmen pegawai dan Kepemimpinan terhadap Kepuasan Kerja dan produktivitas kerja Karyawan PD. Wonoagung Sejahtera di Gresik, Thesis Program Magister Manajemen, Surabaya, Universita Katolik Widya Mandala Surabaya. Jurnal.

Darmawan. 2013. Metode Penelitian Kuantitatif. Bandung: Remaja Rosdakarya.

Edyun, Neti. 2012. Hubungan Antara Stres Kerja Dengan Produktivitas Kerja

Karyawan. Yogyakarta: Pustaka Pelajar.

Ernie, Tisnawati Sule. 2015. Pengantar Manajemen. Depok: Prenadamedia Group.

Fattah, Nanang. 2014. Landasan Manajemen Pendidikan. Bandung: Remaja Rosdakarya.

Flippo, Edwin B. 2012. Personel Management (Manajemen Personalia), 
Edisi. VII Jilid II, Terjemahan Alponso S. Jakarta: Erlangga.

Gie, The Liang. 2010. Administrasi Perkantoran Modern. Yogyakarta: Liberti. Griffin, Ricky W., and Moorhead, Gregory., 2014. Organizational Behavior:

Managing People and Organizations. Eleventh Edition. USA: South Western.

Hamid, Sanusi. 2013. Manajemen Sumber Daya Manusia Lanjutan. Yogyakarta: CV Budi Utama.

Hanjaya Siaputra. 2013. Analisis pengaruh lingkungan kerja, pengawasan dan pelatihan terhadap produktivitas karyawan di Room Devision Hotel Surabaya. Jurnal.

Hasibuan, Malayu S.P. 2012. Manajemen Dasar Pengertian dan Masalah. Jakarta: Bumi Akasara.

Heizer, Jay dan Render, Barry. 2011. Manajemen Operasi. Edisi Sebelas.. Jakarta: Salemba Empat.

Intan Joseph. 2013. Analisis pengaruh lingkungan kerja fisik dan non fisik terhadap produktivitas karyawan di rumah sakit Minahasa. Skripsi.

Jannah, Lina Miftahul. 2018. Metode Penelitian Kuantitatif Teori dan Aplikasi. Jakarta : Pt. Raja Grafindo Persada.

Jemmy, Rumengan. 2013. Metodologi Penelitian. Jakarta: Cipta Pustaka Media Perintis.

Kansil, C.S.T. 2012. Pokok-Pokok hukum kepegawaian Republik Indonesia. Jakarta: Pradnya Paramitha.

Kartono, Kartini, 2012. Pemimpin dan Kepemimpinan: Apakah Pemimpin Abnormal Itu? Jakarta: RajaGrafindo Persada.

Komaruddin. 2012. Ensiklopedia Manajemen. Jakarta: Bumi Aksara.

Lewa dan Subowo. 2015. Pengaruh Kepemimpinan, Lingkungan Kerja Fisik Dan Kompensasi Terhadap Kinerja Karyawan Di PT. Pertamina (Persero) Daerah Operasi Hulu Jawa Bagian Barat, Cirebon. Jurnal Sinergi. Hal 129 - 140.

Luthan, Fred. 2015. Prilaku Organisasi. Yogyakarta: ANDI.

Mangkunegara. 2012. Manajemen Sumber Daya Manusia. Bandung: Remaja Rosdakarya.
Mathis, Robert L. dan Jackson, John H. 2012. Manajemen Sumber Daya Manusia Edisi 9, dialih bahasakan oleh Jimmy Sadeli dan Bayu Prawira Hie. Jakarta: Salemba Empat.

Maurits, Setyawati. 2010. Selintas tentang kelelahan kerja. Yogyakarta: Amara Books.

Moekijat. 2012. Evaluasi Pelatihan Dalam Rangka Peningkatan Produktivitas. Bandung: Mandar Maju.

Mulyadi. 2017. Sistem Informasi Akuntansi. Jakarta: Salemba Empat. Nasution, Fuad Abdillah. 2011. Analisis Pengaruh Lingkungan Kerja Dan

Insentif Terhadap Produktivitas Kerja Karyawan Di Pabrik Kelapa Sawit PT. Perkebunan Nusantara IV Kebun Air Batu Asahan.Tesis Medan: FE USU.

Nitisemito, Alex S. 2011. Manajemen Personalia. Jakarta: Ghalia Indonesia. Notoatmodjo, $\quad$ Soekidjo. 2012. Pengembangan Sumber Daya Manusia. Jakarta: Rineka Cipta.

Nurhayati, Eti. 2012. Manajemen Sumber Daya Manusia. Bandung: Yrama Widya.

Purwaningsih, Ratna. 2018. Manajemen Sumber Daya Manusia. Bandung : PT. Refika Aditama.

Rachman, Taufiq. 2011. Manajemen Sumber Daya Manusia Perusahaan. Bogor: Ghalia Indonesia.

Robbins, Stephen P. 2013. Perilaku Organisasi. Jakarta: Salemba Empat. Safrudin, Alwi. 2012. Manajemen Sumber Daya Manusia. Yogyakarta: BPFE. Saksono, Slamet. 2011. Administrasi Kepegawaian. Yogyakarta: Kanisius.

Satriadi. 2015. Pengaruh Kepemimpinan Kepala Sekolah Terhadap Kinerja Guru. Jurnal penelitian. Sekolah Tinggi Ilmu Ekonomi Pembangunan Tanjungpinang, Kepulauan Riau.

Satriadi. 2016. Pengaruh Kepemimpinan Terhadap Kinerja. Jurnal penelitian. Saydam, Gauzali. 2010. Manajemen Sumber Daya Manusia (Human Resource) Suatu Pendekatan Mikro. Jakarta: Djambatan.

Schultz, D. 2012. Human Resource Management. New York: Pearson. Sedarmayanti. 2010. Manajemen Sumber Daya Manusia Strategik. Bogor: Ghalia Indonesia. 
, 2011. Tata Kerja dan Produktivitas

Kerja. Bogor: Ghalia Indonesia. 2012. Sumber Daya Manusia dan Produktivitas Kerja. Bogor: Ghalia Indonesia.

2014. Manajemen Sumber Daya

Manusia. Bogor: Ghalia Indonesia.

Setiawan dan Ghazali. 2010. Pengaruh

Kompetensi Individu, Insentif dan Motivasi Intrinsik Terhadap Kinerja Pegawai Perum Bulog Divre Kampar. Jurnal.

Setiyawan, Ade. 2015. Metodologi Penelitian Manajemen Sumber Daya Manusia. Jakarta : PT. Raja Grafindo Persada.

Sholihah, Qomariyatus. Dan Wahyudi Kuncoro. 2012. Keselamatan Kesehatan Kerja: Konsep Perkembangan dan Implementasi Budaya Keselamatan. Jakarta: EGC.

Siagian, Sondang P. 2012. Teori dan Praktek Kepemimpinan. Jakarta: CV Haji Masagung. 2013. Administrasi Pembangunan. Jakarta: CV Haji Masagung. 2015. Manajemen Sumber Daya Manusia. Jakarta: CV Haji Masagung.

Simamora, Henry. 2012. Manajemen Sumber Daya Manusia. Edisi 1. Yogyakarta: STIE YKPN Yogyakarta.

Sinungan, Muchdarsyah. 2011. Produktivitas Apa dan Bagaimana. Jakarta: Bumi Aksara.

Situmorang \& Juhir. 2011. Manajemen Sumber Daya Manusia. Bandung: Pustaka Setia.

Soehardi, Sigit. 2013. Perkembangan Pikiran - Pikiran Manajemen dan Pendekatan-Pendekatannya. Yogyakarta: Armurrita.

Solaeman, M. Munandar. 2014. Ilmu Sosial Dasar Teori dan Konsep Ilmu Sosial. Bandung: PT Eresco.

Sopiah. 2018. Perilaku Organisasi. Yogyakarta. Andi.

Sugiyono. 2010. Metode Penelitian Kualitatif, Kuantitatif dan R\&D. Bandung: Alfabeta.

, 2012. Metode Penelitian

Pendidikan. Bandung: Alfabeta. 2013. Metode Penelitian

Manajemen. Bandung: Alfabeta.
2016. Metode Penelitian dan

Pengembangan. Bandung: Alfabeta.

Sulistiani. 2013. Manajemen Sumber Daya Manusia. Yogyakarta: Gava Medika.

Suma'mur. 2015. Kesehatan dan Keselamatan Kerja. Jakarta: PT. Gunung Agung.

Sumarlin. 2014. Manajemen Birokrasi Indonesia. Jakarta: Ghalia Indonesia. Sumarwan, Ujang. 2013. Prilaku Konsumen. Bandung: Alfabeta.

Sumodiningrat. 2011. Pengantar Statistika. Jakarta: Andi.

Supriyanto, Achmad Sani. dan Masyhuri Machfudz. 2010. Metodologi Riset: Manajemen Sumberdaya Manusia. Malang: UIN-Maliki Press.

Sutrisno, Edy. 2011. Manajemen Sumber Daya Manusia. Jakarta: Pranada Media Group.

2014. Manajemen Keuangan Teori Konsep dan Aplikasi. Jakarta: Pranada Media Group. 2016. Metodologi Research. Jakarta: Pranada Media Group. Trenggono. 2018. Metode Penelitian Manajemen. Jakarta: Rajawali Pers.

Ukas, Maman. 2014. Manajemen: Konsep, Prinsip dan Aplikasi. Bandung: Agnini.

Viona Malonda. 2013. Pengawasan, lingkungan kerja dan Motivasi Kerja Pengaruhnya Terhadap Produktivitas Kerja Karyawan PT. Matahari Megamall Manado. Jurnal. 